\title{
A narrative review of echocardiography in infective endocarditis of the right heart
}

\author{
Christos G. Mihos ${ }^{1}$, Francesco Nappi ${ }^{2}$ \\ ${ }^{1}$ Echocardiography Laboratory, Columbia University Division of Cardiology, Mount Sinai Heart Institute, Miami Beach, FL, USA; ${ }^{2}$ Department of \\ Cardiac Surgery, Centre Cardiologique du Nord de Saint-Denis, Paris, France \\ Contributions: (I) Conception and design: All authors; (II) Administrative support: F Nappi; (III) Provision of study materials or patients: CG \\ Mihos; (IV) Collection and assembly of data: CG Mihos; (V) Data analysis and interpretation: All authors; (VI) Manuscript writing: All authors; (VII) \\ Final approval of manuscript: All authors. \\ Correspondence to: Christos G. Mihos, DO. Director, Echocardiography Laboratory, Columbia University Division of Cardiology, Mount Sinai Heart \\ Institute, DHMT Suite 2070, 4300 Alton Road, Miami Beach, FL 33140, USA. Email: Christos.Mihos@msmc.com; drcmihos@gmail.com.
}

\begin{abstract}
Infective endocarditis (IE) is characterized by bacterial or fungal masses that form in the cardiac chambers and valves, and in severe cases invade the endocardium or intra-cardiac vessels. Rightsided IE accounts for $5 \%$ to $10 \%$ of cases, with a low mortality cited at $6 \%$. A history of intravenous drug abuse (IVDU) is present in $90 \%$ of isolated right-sided IE cases, with normal intra-cardiac anatomy prior to infection in approximately $80 \%$. Nevertheless, up to $50 \%$ of patients require early surgical intervention which is associated with significant peri-operative morbidity. Echocardiography is the gold standard for diagnosis with a sensitivity of $80 \%$ for the transthoracic modality and $95 \%$ for transesophageal studies; it provides important clinical information regarding the severity of infection and development of secondary complications. This includes identification of active infective vegetations, healed IE, prosthetic valve IE, and abscess formation and rupture. Prompt clinical, microbiologic, and imaging assessment of patients with suspected left or right-sided IE is of paramount importance and is reflected in the modified Duke criteria, the well-validated algorithm for accurate and timely diagnosis of IE. Data suggests the criteria sensitivity may be decreased in right-sided IE only, and thus, care must be taken to perform skilled and detailed echocardiographic assessments of the right heart in suspected cases. Herein we provide a review of IE of the right heart, with a focus on pathophysiology and its echocardiographic presentation and characteristics.
\end{abstract}

Keywords: Echocardiography; infective endocarditis (IE); right ventricle; tricuspid valve (TV); vegetation

Submitted Jul 08, 2020. Accepted for publication Nov 27, 2020.

doi: $10.21037 /$ atm-20-5198

View this article at: http://dx.doi.org/10.21037/atm-20-5198

\section{Introduction}

Infective endocarditis (IE) is characterized by the formation of bacterial or fungal masses within the cardiac chambers, the semilunar or atrioventricular valves, and in severe cases the mural endocardium or intra-cardiac vessels. Acute bacterial IE is most often caused by staphylococcus aureus infection and progresses rapidly to a systemic immune response syndrome and sepsis (1). Subacute IE tends to be a more insidious disease process resulting from infection by streptococcal, enterococcal, or gram-negative coccobacilli species.
Native valve right-sided IE accounts for $5 \%$ to $10 \%$ of documented cases with a low mortality cited at $6 \%$ $(2,3)$. However, up to $50 \%$ of patients will require surgical intervention which confers a significant morbidity and risk for readmission and heart failure $(4,5)$.

Echocardiography is the gold standard for the diagnosis of IE, with a sensitivity of $80 \%$ for the transthoracic modality and $95 \%$ for transesophageal studies $(6,7)$. Detailed echocardiographic examinations provide important clinical information regarding the extent of infection, intra-cardiac structures involved, and secondary 
complications. This includes cardioembolic events, which occur most commonly to the pulmonary circulation in right-sided IE, and can lead to devastating sequela. A high index of suspicion, prompt clinical and imaging evaluation, and early recognition are standard of care. Herein we provide a review of IE of the right heart, with a focus on pathophysiology and its echocardiographic presentation and characteristics. We present the article in accordance with the Narrative Review reporting checklist (available at http:// dx.doi.org/10.21037/atm-20-5198).

\section{Methods}

A literature review was performed using PubMed, EMBASE, Ovid, and the Cochrane Library, of all scientific articles published through May 2020. The Boolean search terms used included: 'echocardiography', 'characteristics', 'infective endocarditis', 'bacterial endocarditis', 'right heart', 'right ventricle', 'right atrium', 'tricuspid valve', 'pulmonic valve', 'IVDU', 'intravenous drug abuse', 'prosthetic valve', and 'pacemaker'. A focus was placed on descriptive studies and reports correlating echocardiographic findings with pathologic diagnosis. Additionally, the echocardiography laboratory imaging archives at Columbia University Division of Cardiology, Mount Sinai Heart Institute (Miami Beach, FL, USA) were referenced.

\section{Epidemiology and etiologic pathogens}

Data from epidemiologic studies in the United States and Europe have shown a stable overall incidence of IE over the past three decades, which has been cited as 2.6 to 7.0 cases per 100,000 patient years $(8,9)$. The major risk factors for the development of left or right-sided IE include rheumatic and congenital heart disease, intra-cardiac devices, exposure to healthcare-associated infections, and end-stage renal disease (10). Additionally, varying degrees of pre-existing valvular dysfunction or degenerative disease is present in the majority of cases. The median age of IE patients is 58 years, with a two-fold increased risk amongst males (10).

When carefully analyzing the epidemiology of right-sided IE, there are unique characteristics which emerge. More specifically, a history of intravenous drug abuse (IVDU) is elicited from $90 \%$ of patients with isolated right-sided IE, with valves and intra-cardiac structures being normal prior to infection in approximately $80 \%(11,12)$. This is reflected in the doubling of right-sided IE hospitalizations in the United States over the past decade mirroring the similar rise in opioid and heroin abuse, and a shift towards younger patients with more co-morbidities $(13,14)$. Co-infection with human immunodeficiency virus is common, with CD4 counts inversely proportional to clinical outcomes and morbidity; however, this appears to be related to shared risk factors as opposed to causality (15).

\section{Pathogenesis}

\section{Nonbacterial thrombotic endocarditis (NBTE)}

In both left and right-sided IE, the inciting factor is the development of NBTE. The nidus occurs with deposition of platelet and fibrin aggregates on the atrial surface of the mitral and tricuspid valves (TVs), most often in the setting of valvular insufficiency or endothelial damage at the coaptation point; less common is seeding on the atrial or ventricular walls, or subvalvular apparatus $(16,17)$. It is important to restate that in the majority of patients, the valvular endothelium and function is normal prior to IE, and there is a greater impact from specific bacterial surface molecules and the host's serum bactericidal activity on the natural course of IE. Indeed, interaction between a tricuspid regurgitant jet flowing between the higher-pressure right ventricle and the low-pressure right atrium (RA) provides impetus for secondary infection of the platelet-fibrin aggregate by circulating systemic bacteria, triggering the transition of NBTE to TV IE (18).

\section{Transition from nonbacterial thrombotic to bacterial IE}

Although incompletely understood, it has been generally agreed upon that the intrinsic virility of the infecting organism and upregulation of the coagulation and inflammatory cascades are pivotal in the transition from NBTE to bacterial IE $(8,19,20)$. Bacterial adhesins, which are surface molecules integral to the cellular interaction between host and pathogen, vary in their importance between organisms. These include fibronectin, fibrinogenbinding surface protein, and tissue thromboplastin in staphylococcus; polysaccharide and dextran matrix molecules in streptococci; and, collagen adhesins and associated biofilm infiltration in enterococci (21).

Once established the vegetation grows into a variablesized mass of platelet, fibrin, white and red blood cells, phagocytes, and dense clumps of bacteria $(21,22)$. The extent and aggressiveness of bacterial-platelet-neutrophil interactions are important mediators of vegetation size 


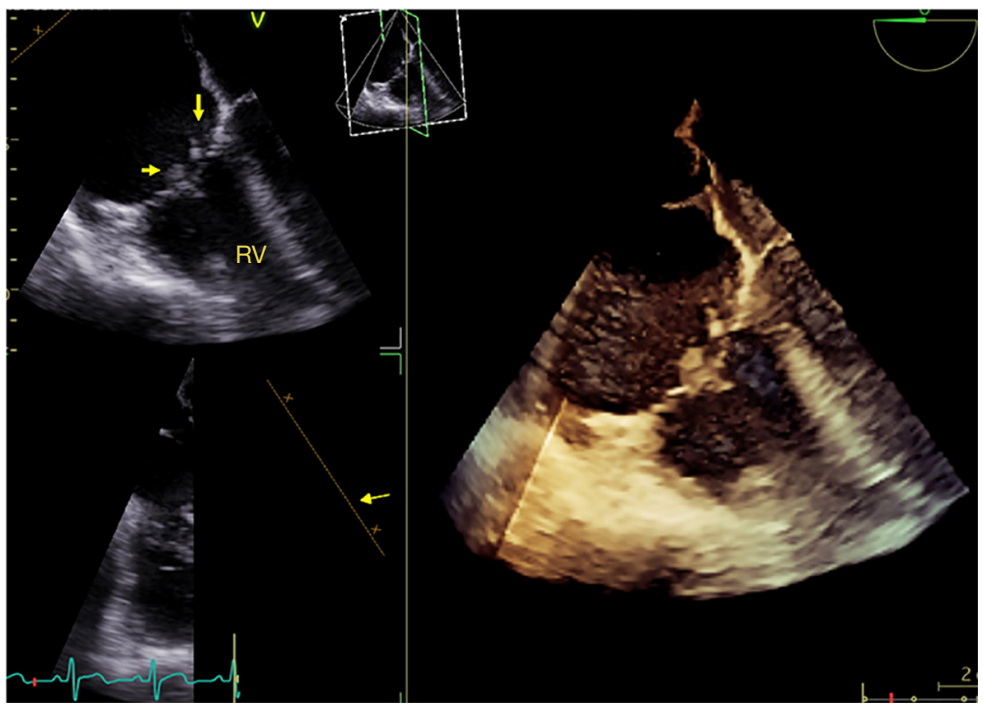

Figure 1 IE of the TV. Mid transesophageal echocardiography RV-focused view at 0 degrees. Multiple amorphous vegetations (arrows) are attached to the atrial and ventricular sides of the TV (left panel). Three-dimensional reconstruction of the right heart is seen in the larger right panel. IE, infective endocarditis; TV, tricuspid valve; RV, right ventricular.

and morphology, which often contain a core of very high bacterial concentration and are essentially avascular $(21,23)$. Neovascularization and fibroblast-mediated connective tissue formation occurs as IE is treated and the endothelium begins to heal (8). Phagocytosis and clearance of infected tissue materials progresses over months, regardless of the treatment approach.

\section{Echocardiographic features of right-sided IE}

As previously discussed, while transthoracic echocardiography is the initial diagnostic imaging test of choice in the workup of bacteremia or suspected IE, the gold standard is two- and three-dimensional transesophageal echocardiography given their superior resolution and sensitivity. The hallmark of the disease is the development and echocardiographic identification of valvular or endocardial vegetations, which care characteristically similar in both left and right-sided IE. However, the increased morbidity and mortality of the disease is driven by progressive infection that results in extensive destruction of intra-cardiac structures, and the ensuing clinical and hemodynamic sequelae.

\section{Native valvular and endocardial vegetations}

In general, infective vegetations are amorphous, mobile, and may be of variable size-from a few millimeters to centimeters large (24-26). In the acute phase they typically appear soft and friable on echocardiographic examination, while in subacute or chronic stages the vegetations can become partially or entirely calcified ('healed') and fixated to the underlying structure. In right-sided IE, infective vegetations of the TV may be present on the leaflet tips, atrial or ventricular portions of the leaflet body, or the valve annulus (27) (Figure 1). In early disease the primary findings may only be increasing thickness and an irregular leaflet contour, as the biofilm seeds infection. Aggressive infection can spread to the subvalvular apparatus and result in destruction of the supporting structures and chordae tendinae, resulting in leaflet flail (Figure 2). In these instances, signs of right ventricular (RV) volume overload, with paradoxical interventricular septal motion and flattening, may be appreciated. Native pulmonic valve (PV) IE is most often associated with underlying congenital heart disease or IVDU, with the latter presentation being far less common than tricuspid infection (Figure 3). Vegetation characteristics and the causative microorganisms are also similar.

\section{Healed valvular endocarditis}

Improved imaging techniques and the use of harmonic 


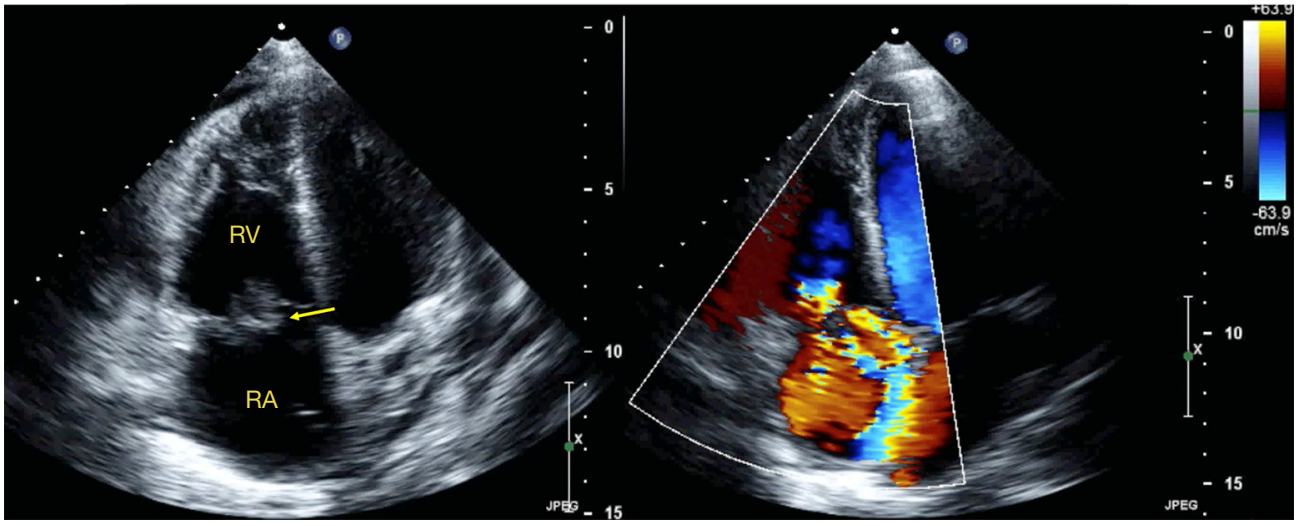

Figure 2 TV IE with valvular destruction. Transthoracic echocardiography apical RV-focused view. In the left panel there is diffuse echogenic thickening of the TV, with 'shaggy' vegetations noted on the anterior and septal leaflets. Infection and rupture of chordae tendinae has resulted in a flail anterior TV leaflet (arrow) and severe medially-directed tricuspid regurgitation (right panel). TV, tricuspid valve; IE, infective endocarditis; RV, right ventricular; RA, right atrium.

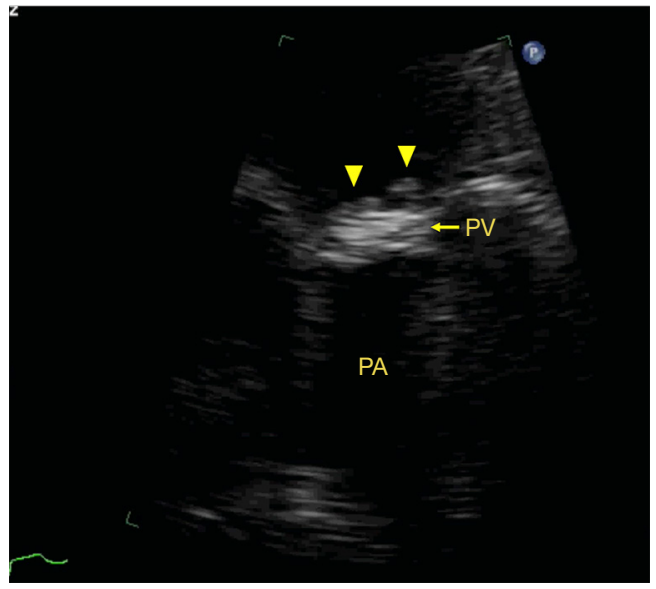

Figure 3 IE of the PV. Transthoracic echocardiography parasternal short-axis view with a focus on the PV. There is severe congenital pulmonic stenosis, with heavy degenerative thickening and calcification of the PV leaflets. There is extensive superimposed infective vegetations on the ventricular side of valve (triangle). IE, infective endocarditis; PV, pulmonic valve; PA, pulmonary artery.

ultrasound has improved the ability of echocardiography to qualitatively differentiate active IE from old or 'healed' vegetations. This is based on the observation that in the chronic stages of IE the infective vegetations decrease in size, calcify, and become more echogenic, which is the result of collagen deposition and extensive fibrocalcific inflammation $(28,29)$. It is prudent to compare serial echocardiograms to assess for the natural disease progression, and to remain vigilant for re-infection which is a substantial risk in this population.

\section{Prosthetic valve endocarditis (PVE)}

PVE is a more challenging disease in regards to imaging diagnosis as a result of prosthesis-related artifacts and shadowing, and a generally sicker population with more cardiovascular pathology. The echocardiographic characteristics of PVE vegetations are similar to what is observed with native valve disease (30). Transesophageal echocardiography is often necessary for definitive diagnosis, particularly with involvement of the prosthetic sewing ring or in the setting of underlying calcification or pannus overgrowth; in severe cases vegetative material may not be reliably differentiated from pannus or superimposed thrombus. When infection involves more than a third of the annular circumference with extension into the fibrous skeleton and sutures, the prosthesis may become dehisced with visible 'rocking' on echocardiography (31).

\section{Aortic root abscess with right heart involvement}

Abscess formation is defined as a purulent infective and necrotic collection of fluid, which at the aortic root occurs between layers of the aortic wall, and most commonly in the acute setting of staphylococcal or enterococcal IE. On echocardiography the infected aortic root appears thickened and echogenic, and may be subtle in the early stages to centimeters thick in aggressive infection (Figure 4) (32). The abscess is highly echolucent, reflecting the 


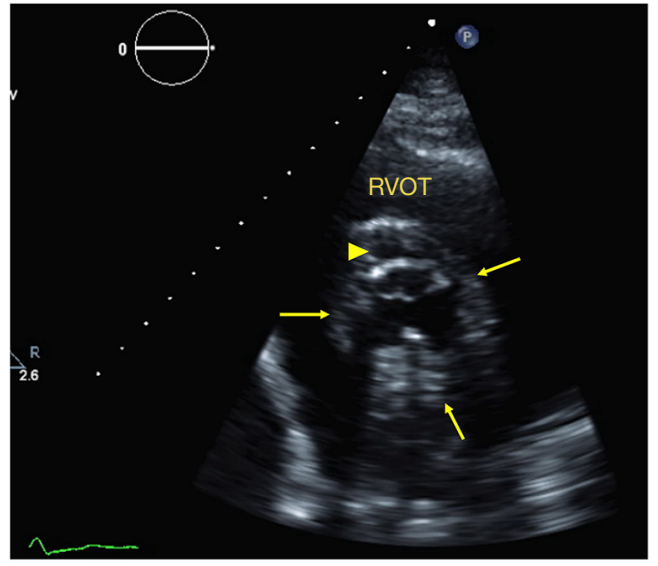

Figure 4 Bioprosthetic AV IE and aortic root abscess. Transthoracic echocardiography parasternal short-axis view at the level of the AV. A bioprosthetic AV is present with circumferential aortic root thickening and abscess formation (arrows). The echolucent space located anterior is a pocket of fluid within the abscess (triangle), which increases the risk of fistula formation or rupture into other cardiac chambers, and is adjacent to the RVOT. $\mathrm{AV}$, aortic valve; IE, infective endocarditis; RVOT, right ventricular outflow tract.

ultrasound properties of fluid; if a communication with the system aortic lumen is present, a systolic bulging motion from capsular flow can be appreciated, and the condition is termed a mycotic aneurysm. Invasion of the abscess into nearby vascular structures, such as the main pulmonary artery (PA), can occur (Figure 5).

Aggressive infection of the left coronary cusp of the aorta may expand to the intervalvular fibrosa and anterior mitral leaflet, affecting the left heart (33). However, infection of the right or non-coronary cusps risks extension to right heart structures (34). With an aortic root abscess and right coronary cusp involvement, the membranous and muscular portions of the interventricular septum can become secondarily infected. This can result in formation of a ventricular septal defect with interventricular shunting, or direct endothelial IE of the right ventricle or RV outflow tract (RVOT) (35) (Figure 6). Infection of the non-coronary cusp also risks involvement of the interventricular system, albeit in a more posterior location. A ruptured abscess in this anatomic location will lead to fistulous communication into the basal right ventricle or RA (35). Finally, bacterial seeding into the mid and distal interventricular septum is possible, which most readily presents with conduction system abnormalities. Any portion of the septum can form aneurysmal abscess cavities that degenerate into necrotic defects and interventricular shunting (36).

\section{Uncommon findings and differentials of right-sided IE}

Very large vegetations on the aortic valve (AV) cusps have been shown to carry a risk of coronary artery flow obstruction or particle embolization leading to coronary occlusion (37). Careful attention and a high index of suspicion, both clinically and echocardiographically for new electromechanical complications and wall motion abnormalities in the right coronary artery myocardial territory, is paramount. Purulent pericarditis has been reported in cases of both left and right-sided IE, and is most commonly the result of hematogenous seeding or rupture of mycotic aneurysm into the pericardial space (38). Serous effusions as a result of systemic inflammation are common and non-specific to IE. Finally, the vena cava should be imaged and carefully assessed for thrombus and vegetation formation at the site of pacemaker wires and catheters (Figure 7).

There are numerous other pathologic and nonpathologic echocardiographic right heart findings that may be misinterpreted or confer a challenge in differentiating from IE. These include, but are not limited to: (I) Chiari network, the embryologic remnant of the sinus venosus that originates at the right atrial-inferior vena cava junction; (II) eustachian valve, the embryonic remnant of the sinus venosus valve (Figure 8); (III) atrial septal aneurysm, which may be mobile or non-mobile and prominent dependent upon the respective atrial pressure; (IV) interatrial septal lipomatous hypertrophy, caused by benign fatty infiltration within the atrial tissue; (V) annular calcification, which creates a challenge when severe in differentiating identifying vegetations particularly when in stages of healing; (VI) RV moderator band, a normal fibrous structure through which the right bundle branch traverses; and, (VII) PA catheter or pacemaker wire(s), which are visualized as linear echodensities in the right heart, RVOT, and/or main PA, with variable mobility and creation of ultrasound artifacts (39-44).

\section{Diagnosis and management}

Prompt clinical, microbiologic, and imaging assessment of patients with suspected left or right-sided IE is of paramount importance. This includes risk stratification, blood cultures, transthoracic echocardiography, and 


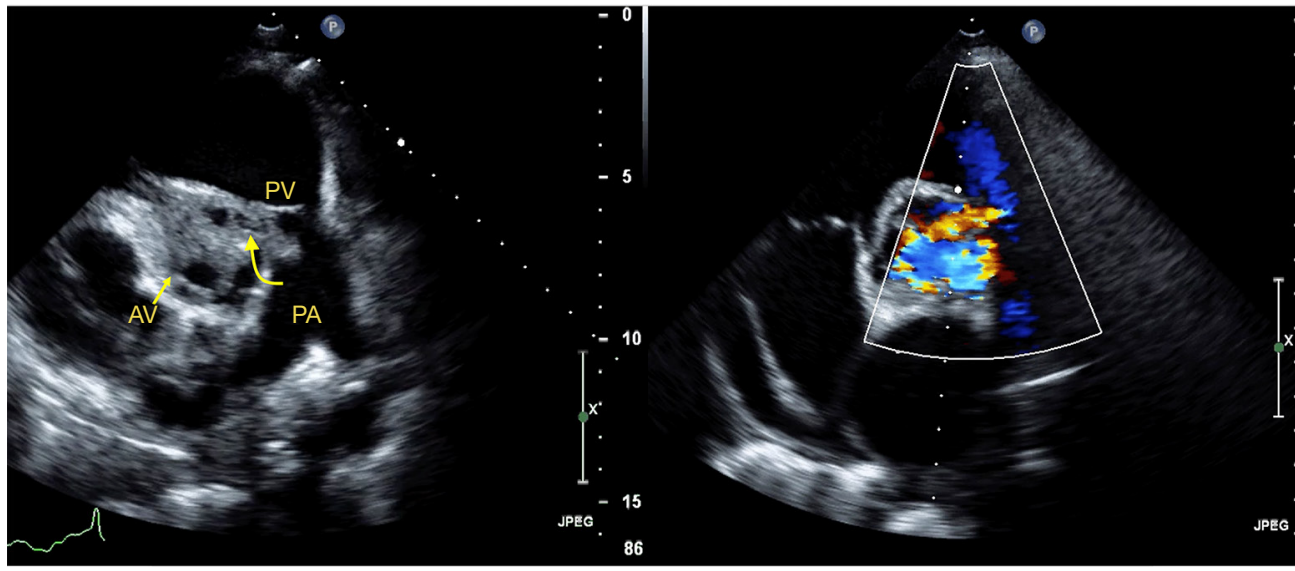

Figure $5 \mathrm{AV}$, aortic root, and PA IE. Transthoracic echocardiography parasternal short-axis view at the level of the PV and PA. In the left panel there is diffuse echogenic thickening of the AV and thickening of the aortic root consistent with AV endocarditis and aortic root abscess. Tissue destruction has resulted in an aorta-to-PA fistula (curved arrow), with flow visualized by color Doppler interrogation (right panel). AV, aortic valve; PA, pulmonary artery; IE, infective endocarditis; PV, pulmonic valve.

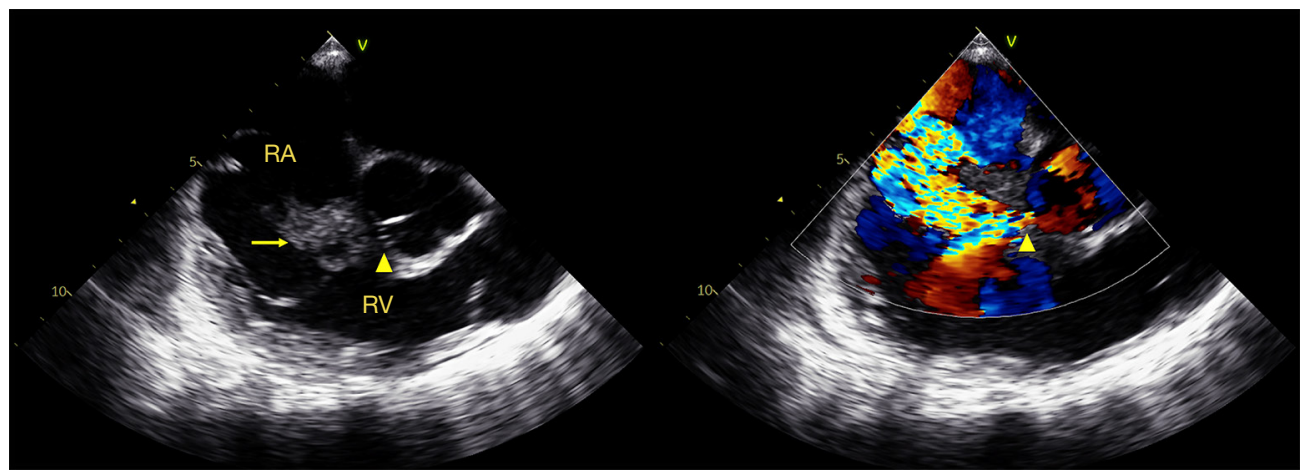

Figure 6 TV IE with an 'acquired' ventricular septal defect. Mid transesophageal echocardiography short axis view at 60 degrees. In the left panel there is large vegetation (arrow) attached to and encasing the septal TV leaflet, posterolateral aortic root, and subaortic interventricular septum. An 'acquired' membranous ventricular septal defect from infection and destruction of the suboartic interventricular septum is noted (triangle), with a large left-to-right interventricular shunt present (right panel). TV, tricuspid valve; IE, infective endocarditis; RA, right atrium; RV, right ventricle.

identification of patients who may require early surgical intervention. Point of care ultrasound (PoCUS), or limited bedside echocardiography, is used to complement the traditional physical examination and expedite management. Standard parasternal and short axis views on PoCUS provide a quick and efficient sweep of the cardiac valves to assess for aggressive disease or structural complications due to IE that require immediate intervention (45). The modified Duke criteria provides clinicians and surgeons with a robust and well-validated algorithm for accurate and timely diagnosis of IE based on the presence of two major criteria, one major and three minor criteria, or five minor criteria (Figure 9) (46). It should be noted, however, that the criteria sensitivity may be decreased in right-sided IE only (47). The choice of antimicrobial agent is based on the virility and susceptibility of the pathogen, with typical duration of 4 to 6 weeks. Repeat echocardiography is indicated in the development of septic or embolic complications, congestive heart failure, or new valvular regurgitation or conduction system abnormalities.

The decision and timing of surgical intervention for right-sided IE is driven primarily by disease burden, and 


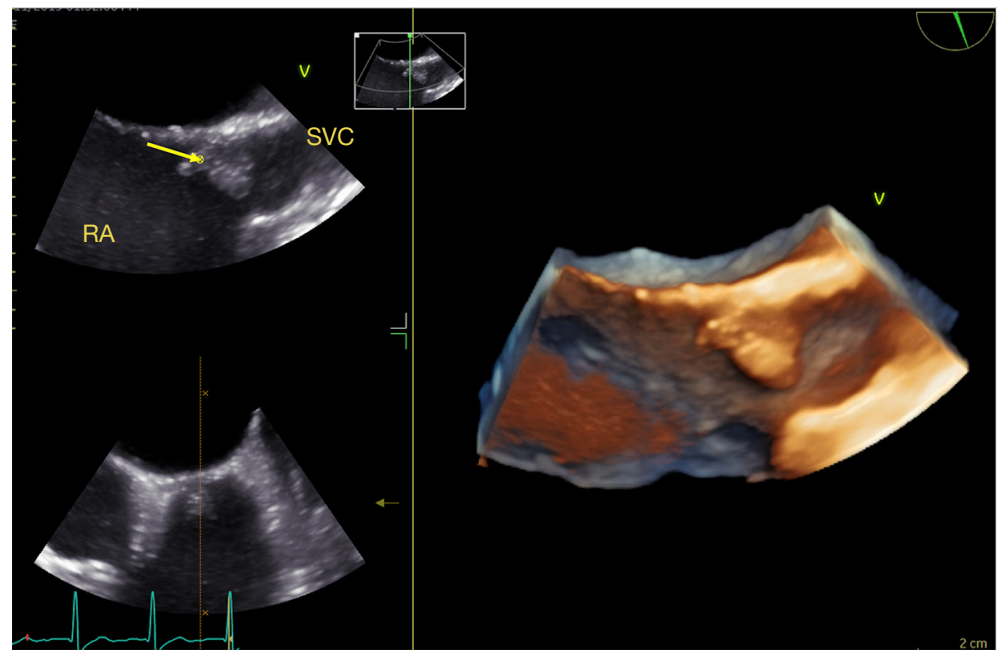

Figure 7 Right atrial IE. Mid transesophageal echocardiography bicaval view at 110 degrees. In the left panel there is large vegetation (arrow) attached to the junction of the right interatrial septum and the ostium of the SVC. Three-dimensional reconstruction of the findings is seen in the right panel. The vegetation presumably resulted from indwelling catheter trauma creating a nidus for endocardial infection. IE, infective endocarditis; SVC, superior vena cava; RA, right atrium.

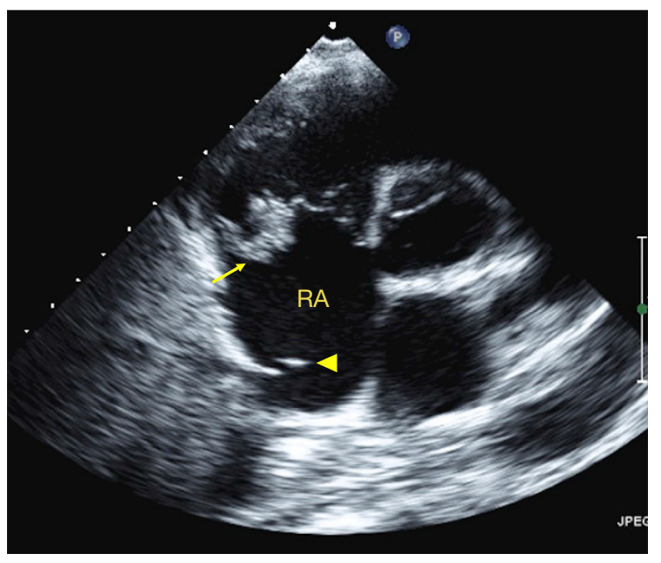

Figure 8 TV endocarditis and normal anatomic variants. Transthoracic echocardiography parasternal short-axis view with a focus on the TV. There is extensive TV endocarditis with encasement of the anterior tricuspid leaflet by vegetation (arrow). In the superior and lateral RA is the eustachian valve, which can be mistaken for vegetation, thrombus, or mass (triangle). TV, tricuspid valve; RA, right atrium.

the risk of progressive infection with intra-cardiac or systemic complications. Conventional criteria include: (I) highly resistant bacterial or fungal pathogens; (II) large mobile vegetations (>10-20 mm); (III) persistent bacteremia despite antibiotic therapy; and, (IV) septic pulmonary emboli (12). In instances of valvular IE, the timing, surgical approach, performance of valve repair or replacement, and duration of antibiotic therapy requires a multi-disciplinary team approach including a cardiologist, cardiac surgeon, infectious disease specialist, and internist, at a minimum. For prosthetic valve IE, early surgery has been shown in a large meta-analysis to lower the risk of 30-day mortality and increase survival at mid-term follow-up, with a similar rate of IE recurrence when compared with initial conservative medical therapy (48). Finally, indwelling catheters, ports, pacemaker wires, and arteriovenous fistulas should be removed, and re-implantation performed in cases where the devices are required and ideally after completion of antibiotic therapy.

Once surgical intervention has been decided upon in cases of TV IE, the performance of valve repair or replacement is dependent upon several factors including patient age and co-morbidities, extent of valvular destruction and associated complications, and surgeon experience. Nevertheless, as in mitral valve disease, repair of the TV is preferable (49). With either approach it is critical to: (I) address the pathology promptly once the organism has been identified and antibiotics are instituted; and, (II) aggressively debride the infected tissues to at least a $2 \mathrm{~mm}$ margin with non-infected tissue. Patients with right-sided IE in the setting of IVDU and prohibitive surgical risk pose a challenge given their high risk of reinfection as a result of IVDU relapse, as well as underlying co-morbidities. When 


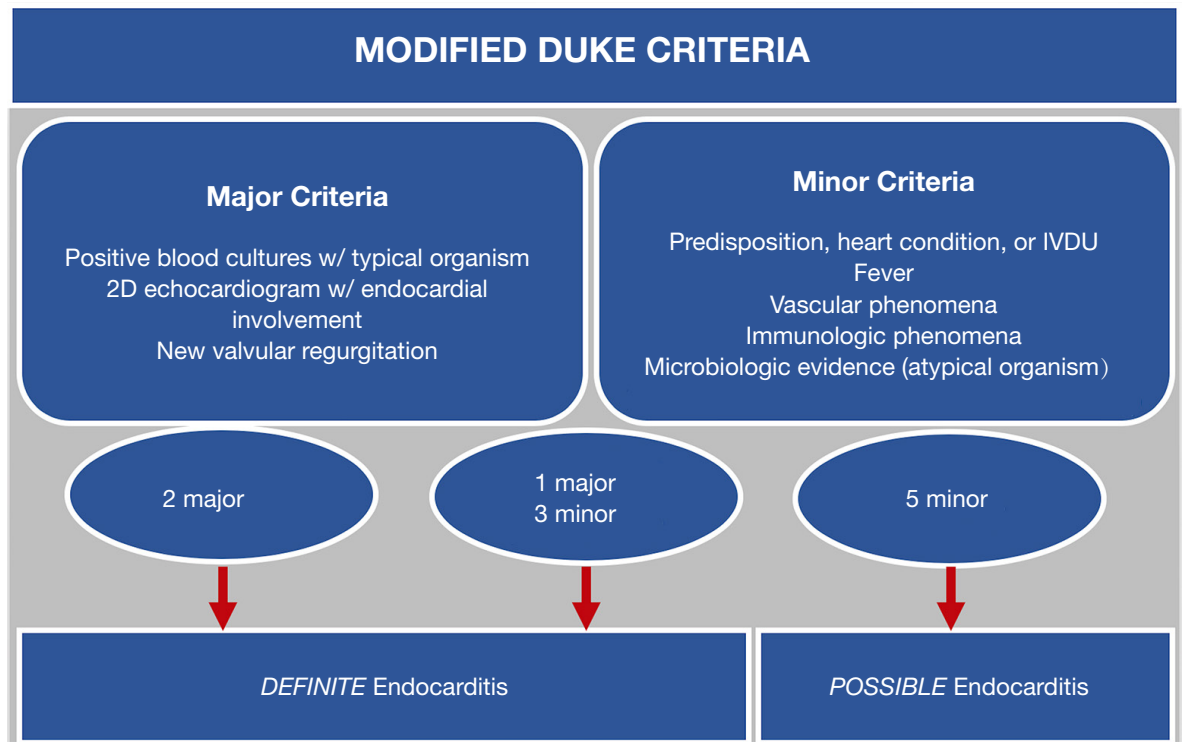

Figure 9 The modified duke criteria for the diagnosis of IE. IE is diagnosed when two major criteria, one major and three minor criteria, or five minor criteria are present. IE, infective endocarditis; IVDU, intravenous drug abuse.

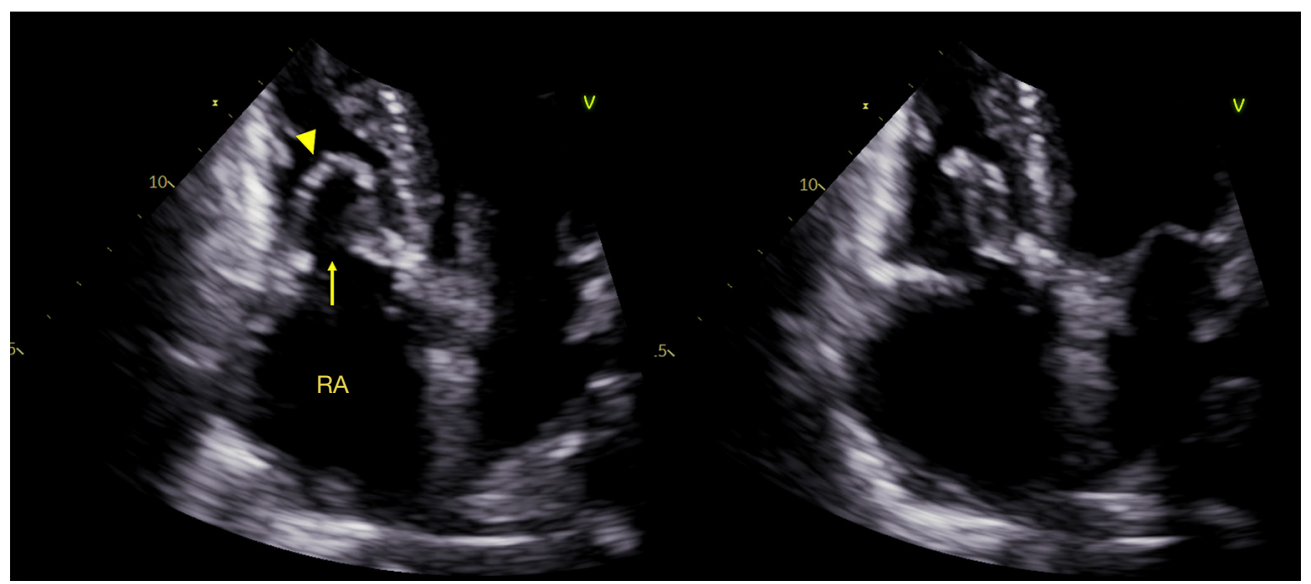

Figure 10 Cylindrical tube pericardial patch reconstruction of the TV. Two-years status post partial tricuspid valvectomy and cylindrical tube pericardial patch reconstruction of the TV (triangle) in a patient with endocarditis due to IVDU. The inflow portion of the tube (arrow) is sutured to the tricuspid annulus, and the outlow to the papillary muscle heads. The low-pressure state of the right heart allows for functioning of the tube as a conduit for flow between the RA and ventricle (left panel), with adequate systolic closure and minimal tricuspid regurgitation (right panel). TV, tricuspid valve; IVDU, intravenous drug a buse; RA, right atrium.

refractory to antibiotic therapy alone, debulking of the vegetation with a veno-venous extracorporeal membranous oxygenation-supported AngioVac system (AngioDynamics, Latham, NY, USA) can be performed safely. This approach allows for a reduction in the burden of friable infective material in the right heart and has been effective in reducing septic pulmonary complications (50). Alternatively, partial or total valvectomy with pericardial patch reconstruction of the TV allows for a more definitive operation, which may appeal to younger patients $(51,52)$ (Figure 10). The pericardial materials are non-antigenic and resistant to infection; nevertheless, mid-term failure from calcification 
and increased tensile stressors has been reported.

\section{Conclusions}

Right-sided IE is a disease process with substantial clinical and socioeconomic ramifications. An early index of suspicion and multi-disciplinary care and treatment planning is of utmost importance to successful medical and surgical management, and in preventing relapse or recurrence. Echocardiography is the gold standard for imaging workup and diagnosis; careful attention to imaging allows for accurate risk stratification, identification of possible intra- and extra-cardiac manifestations, and comprehensive treatment planning.

\section{Acknowledgments}

Funding: None.

\section{Footnote}

Provenance and Peer Review: This article was commissioned by the editorial office, Annals of Translational Medicine for the series "Infective Endocarditis in the 21st Century". The article has undergone external peer review.

Reporting Checklist: The authors have completed the Narrative Review reporting checklist. Available at http:// dx.doi.org/10.21037/atm-20-5198

Conflicts of Interest: Both authors have completed the ICMJE uniform disclosure form (available at http:// dx.doi.org/10.21037/atm-20-5198). The series "Infective Endocarditis in the 21st Century" was commissioned by the editorial office without any funding or sponsorship. FN served as the unpaid Guest Editor of the series and serves as an unpaid editorial board member of Annals of Translational Medicine from Feb 2019 to Jan 2021. CGM served as the unpaid Guest Editor of the series. The authors have no other conflicts of interest to declare.

Ethical Statement: The authors are accountable for all aspects of the work in ensuring that questions related to the accuracy or integrity of any part of the work are appropriately investigated and resolved.

Open Access Statement: This is an Open Access article distributed in accordance with the Creative Commons
Attribution-NonCommercial-NoDerivs 4.0 International License (CC BY-NC-ND 4.0), which permits the noncommercial replication and distribution of the article with the strict proviso that no changes or edits are made and the original work is properly cited (including links to both the formal publication through the relevant DOI and the license). See: https://creativecommons.org/licenses/by-nc-nd/4.0/.

\section{References}

1. Tleyjeh IM, Abdel-Latif A, Rahbi H, et al. A systematic review of population-based studies of infective endocarditis. Chest 2007;132:1025-35.

2. Chahoud J, Sharif Yakan A, et al. Right-sided infective endocarditis and pulmonary infiltrates: an update. Cardiol Rev 2016;24:230-7.

3. Akinosoglou K, Apostolakis E, Marangos M, et al. Native valve right sided infective endocarditis. Eur J Intern Med 2013;24:510-9.

4. Lalani T, Cabell CH, Benjamin DK, et al. Analysis of the impact of early surgery on in-hospital mortality of native valve endocarditis: use of propensity score and instrumental variable methods to adjust for treatmentselection bias. Circulation 2010;121:1005-13.

5. Kiefer T, Park L, Tribouilloy C, et al. Association between valvular surgery and mortality among patients with infective endocarditis complicated by heart failure. JAMA 2011;306:2239-47.

6. Shively BK, Gurule FT, Roldan CA, et al. Diagnostic value of transesophageal compared with transthoracic echocardiography in infective endocarditis. J Am Coll Cardiol 1991;18:391-7.

7. Mügge A, Daniel WG, Frank G, et al. Echocardiography in infective endocarditis: reassessment of prognostic implications of vegetation size determined by the transthoracic and the transesophageal approach. J Am Coll Cardiol 1989;14:631-8.

8. Moreillon P, Que YA. Infective endocarditis. Lancet 2004;363:139-49.

9. Tleyjeh IM, Steckelberg JM, Murad HS, et al. Temporal trends in infective endocarditis: a population-based study in Olmsted County, Minnesota. JAMA 2005;293:3022-8.

10. Murdoch DR, Corey GR, Hoen B, et al. Clinical presentation, etiology, and outcome of infective endocarditis in the 21 st century: the International Collaboration on Endocarditis-Prospective Cohort Study. Arch Intern Med 2009;169:463-73.

11. Miró JM, del Río A, Mestres CA. Infective endocarditis 
in intravenous drug abusers and HIV-1 infected patients. Infect Dis Clin North Am 2002;16:273-95, vii-viii.

12. Baddour LM, Wilson WR, Bayer AS, et al. Infective endocarditis in adults: Diagnosis, antimicrobial therapy, and management of complications: a scientific statement for healthcare professionals from the American Heart Association. Circulation 2015;132:1435-86.

13. Wurcel AG, Anderson JE, Chui KK, et al. Increasing infectious endocarditis admissions among young people who inject drugs. Open Forum Infect Dis 2016;3:ofw157.

14. Wilson LE, Thomas DL, Astemborski J, et al. Prospective study of infective endocarditis among injection drug users. J Infect Dis 2002;185:1761-6.

15. Gebo KA, Burkey MD, Lucas GM, et al. Incidence of, risk factors for, clinical presentation, and 1-year outcomes of infective endocarditis in an urban HIV cohort. J Acquir Immune Defic Syndr 2006;43:426-32.

16. Freedman LR, Valone J Jr. Experimental infective endocarditis. Prog Cardiovasc Dis 1979;22:169-80.

17. Bansal RC. Infective endocarditis. Med Clin North Am 1995;79:1205-40.

18. Durack DT, Beeson PB. Experimental bacterial endocarditis. I. Colonization of a sterile vegetation. Br J Exp Pathol 1972;53:44-9.

19. Nallapareddy SR, Singh KV, Sillanpaa J, et al. Endocarditis and biofilm-associated pili of Enterococcus faecalis. J Clin Invest 2006;116:2799-807.

20. Nallapareddy SR, Singh KV, Murray BE. Contribution of the collagen adhesin Acm to pathogenesis of Enterococcus faecium in experimental endocarditis. Infect Immun 2008;76:4120-8.

21. Werdan K, Dietz S, Löffler B, et al. Mechanisms of infective endocarditis: pathogen-host interaction and risk states. Nat Rev Cardiol 2014;11:35-50.

22. Jung CJ, Yeh CY, Shun CT, et al. Platelets enhance biofilm formation and resistance of endocarditis-inducing streptococci on the injured heart valve. J Infect Dis 2012;205:1066-75.

23. Scheld WM, Valone JA, Sande MA. Bacterial adherence in the pathogenesis of endocarditis. Interaction of bacterial dextran, platelets, and fibrin. J Clin Invest 1978;61:1394-404.

24. Roy P, Tajik AJ, Giuliani ER, et al. Spectrum of echocardiographic findings in bacterial endocarditis. Circulation 1976;53:474-82.

25. Dillon JC, Feigenbaum H, Konecke LL, et al. Echocardiographic manifestations of valvular vegetations. Am Heart J 1973;86:698-704.
26. Spangler RD, Johnson ML, Holmes JH, et al. Echocardiographic demonstration of bacterial vegetations in active infective endocarditis. J Clin Ultrasound 1973;1:126-8.

27. Come PC, Kurland GS, Vine HS. Two dimensional echocardiography in differentiating right atrial and tricuspid valve mass lesions. Am J Cardiol 1979;44:1207-12.

28. Tak T, Rahimtoola SH, Kumar A, et al. Value of digital image processing of two-dimensional echocardiograms in differentiating active from chronic vegetations of infective endocarditis. Circulation 1988;78:116-23.

29. Stafford A, Wann LS, Dillon JC, et al. Serial echocardiographic appearance of healing bacterial vegetations. Am J Cardiol 1979;44:754-60.

30. Arnett EN, Roberts WC. Prosthetic valve endocarditis: clinicopathologic analysis of 22 necropsy patients with comparison observations in 74 necropsy patients with active infective endocarditis involving natural left-sided cardiac valves. Am J Cardiol 1976;38:281-92.

31. Effron MK, Popp RL. Two-dimensional echocardiographic assessment of bioprosthetic valve dysfunction and infective endocarditis. J Am Coll Cardiol 1983;2:597-606.

32. Leung DY, Cranney GB, Hopkins AP, et al. Role of transoesophageal echocardiography in the diagnosis and management of aortic root abscess. Br Heart J 1994;72:175-81.

33. Gonzalez-Lavin L, Scappatura E, Lise M, et al. Mycotic aneurysms of the aortic root: a complication of aortic valve endocarditis. Ann Thorac Surg 1970;9:51-61.

34. Karalis DG, Bansal RC, Hauck AJ, et al. Transesophageal echocardiographic recognition of subaortic complications in aortic valve endocarditis: Clinical and surgical implications. Circulation 1992;86:353-62.

35. Fox S, Kotler MN, Segal BL, et al. Echocardiographic diagnosis of acute aortic valve endocarditis and its complications. Arch Intern Med 1977;137:85-9.

36. Walker N, Bhan A, Desai J, et al. Myocardial abscess: a rare complication of valvular endocarditis demonstrated by $3 \mathrm{D}$ contrast echocardiography. Eur J Echocardiogr 2010;11:E37.

37. Gilbert BW, Haney RS, Crawford F, et al. Two-dimensional echocardiographic assessment of vegetative endocarditis. Circulation 1977;55:346-53.

38. Feigenbaum H. Echocardiographic diagnosis of pericardial effusion. Am J Cardiol 1970;26:475-9.

39. Mayl J, Peters L, Zhao D, et al. Chiari network or catheter-associated thrombus? A rare complication of transseptal access. CASE (Phila) 2019;4:21-4. 
40. Limacher MC, Gutgesell HP, Vick GW, et al. Echocardiographic anatomy of the eustachian valve. Am J Cardiol 1986;57:363-5.

41. Silver MD, Dorsey JS. Aneurysms of the septum primum in adults. Arch Pathol Lab Med 1978;102:62-5.

42. Kleiman AM, Harding LM, Bechtel AJ. Concomitant lipomatous hypertrophy and left atrial mass: distinguishing benign from malignant. Echocardiography 2018;35:534-6.

43. Keren A, Billingham ME, Popp RL. Echocardiographic recognition and implications of ventricular hypertrophic trabeculations and aberrant bands. Circulation 1984;70:836-42.

44. Drinković N. Subcostal M-mode echocardiography of the right atrial wall for differentiation of supraventricular tachyarrhythmias with aberration from ventricular tachycardia. Am Heart J 1984;107:326-31.

45. Hackett AJ, Stuart J. Infective endocarditis: identification and management in the emergency department. Emerg Med Pract 2020;22:1-24.

46. Durack DT, Lukes AS, Bright DK. New criteria for diagnosis of infective endocarditis: utilization of specific echocardiographic findings. Duke Endocarditis Service.

Cite this article as: Mihos CG, Nappi F. A narrative review of echocardiography in infective endocarditis of the right heart. Ann Transl Med 2020;8(23):1622. doi: 10.21037/atm-20-5198
Am J Med 1994;96:200-9.

47. Prendergast BD. Diagnostic criteria and problems in infective endocarditis. Heart 2004;90:611-3.

48. Mihos CG, Capoulade R, Yucel E, et al. Surgical versus medical therapy for prosthetic valve endocarditis: a metaanalysis of 32 studies. Ann Thorac Surg 2017;103:991-1004.

49. Slaughter MS, Badhwar V, Ising M, et al. Optimum surgical treatment for tricuspid valve infective endocarditis: an analysis of the Society of Thoracic Surgeons national database. J Thorac Cardiovasc Surg 2019. [Epub ahead of print].

50. Shmueli H, Thomas F, Flint N, et al. Right-sided infective endocarditis 2020: Challenges and updates in diagnosis and treatment. J Am Heart Assoc 2020;9:e017293.

51. Mihos CG, Pineda AM, Santana O, et al. Tricuspid valve repair with pericardial tube placement via a right minithoracotomy. J Heart Valve Dis 2015;24:338-41.

52. Gerdisch MW, Boyd WD, Harlan JL, et al. Early experience treating tricuspid valve endocarditis with a novel extracellular matrix cylinder reconstruction. J Thorac Cardiovasc Surg 2014;148:3042-8. 